\title{
Aluminum Neurotoxicity - Potential Role in the Pathogenesis of Neurofibrillary Tangle Formation
}

\author{
Daniel P. Perl and William W. Pendlebury
}

\begin{abstract}
Alzheimer's disease is a progressive neurodegenerative disease characterized neuropathologically by the development of large numbers of neurofibrillary tangles in certain neuronal populations of affected brains. This paper presents a review of the available evidence which suggests that aluminum is associated with Alzheimer's disease and specifically with the development of the neurofibrillary tangle. Aluminum salts innoculated into experimental animals produce neurofilamentous lesions which are similar, though not identical, to the neurofibrillary tangle of man. Although a few reports have suggested evidence of increased amounts of aluminum in the brains of Alzheimer's disease victims, such bulk analysis studies have been difficult to replicate. Using scanning electron microscopy with $x$-ray spectrometry, we have identified accumulations of aluminum in neurofibrillary tangle-bearing neurons of Alzheimer's disease. Similar accumulations have been identified in the neurofibrillary tangle-bearing neurons found in the brains of indigenous natives of Guam who suffer from parkinsonism with dementia and amyotrophic lateral sclerosis. This ongoing research still cannot ascribe a causal role of aluminum in the pathogenesis of neurofibrillary tangle formation; however, it does suggest that environmental factors may play an important part in the formation of this abnormality.
\end{abstract}

RÉSUMÉ: La neurotoxicité de l'aluminium: son rôle possible dans la pathogénèse de la formation des enchevêtrements neurofibrillaires. La maladie d'Alzheimer est une maladie neurodégénérative progressive caractérisée au point de vue anatomo-pathologique par le développement d'un grand nombre d'enchevêtrements neurofibrillaires au sein de certaines populations de neurones dans le cerveau des sujets atteints. Cet article présente une revue des données disponibles suggérant que l'aluminium est associée à la maladie d'Alzheimer et plus spécifiquement à la formation des enchevêtrements neurofibrilliares. Des sels d'aluminium injectés à des animaux de laboratoire provoquent la formation de lésions neurofilamenteuses qui sont similaires aux enchevêtrements neurofibrillaires chez l'homme, sans toutefois être identiques. Même si quelques auteurs ont rapporté des observations suggérant que la quantité d'aluminium est augmentée dans le cerveau des patients atteints de la maladie d'Alzheimer, de telles analyses globales ont été difficiles à reproduire. Nous avons identifié des accumulations d'aluminium dans les neurones porteurs d'enchevêtrements neurofibrillaires dans la maladie d'Alzheimer, au moyen de la microscopie électronique avec spectrométrie, à rayons $X$. Des accumulations similaires ont été identifiées dans les neurones porteurs d'enchevêtrements neurofibrillaires dans le cerveau d'indigènes natifs de Guam qui souffrent de parkinsonisme accompagné de démence et de sclérose latérale amyotrophique. Cette recherche qui se poursuit ne peut pas encore attribuer un rôle causal à l'aluminium dans la pathogénèse de la formation des enchevêtrements neurofibrillaires; cependant elle suggère qu'il est possible que des facteurs environnementaux jouent un rôle important dans la genèse de cette anomalie.

Can. J. Neurol. Sci. 1986; 13:441-445

The neurofibrillary tangle, first described by Alzheimer in 1907 , ' and the senile (neuritic) plaque are regarded as the two hallmark neuropathologic alterations seen in the brains of victims of Alzheimer's disease. ${ }^{2.3}$ While one sees numerous examples of these two pathologic changes in brain specimens from the severely demented, the brains of non-demented elderly individuals also contain small numbers of identical lesions. ${ }^{4,5}$ Although age represents a significant factor, these histologic lesions likely represent the reaction of the nervous system to unidentified insults. Whether these insults are genetic, meta- bolic, toxic, infectious or immunologic remains a mystery. Over the past several years, evidence has accumulated to suggest that the presence of aluminum in neurons is associated with neurofibrillary tangle formation and may represent a pathogenetic factor for Alzheimer's disease. In this report, we will review this evidence and discuss these findings in the context of current concepts of Alzheimer's disease.

Aluminum Neurotoxicity in Animals

The potential association of aluminum and Alzheimer's disease began with the virtually simultaneous reports of Klatzo 
and co-workers ${ }^{6}$ and of Terry and Pena ${ }^{7}$ describing the induction of neurofibrillary degeneration in rabbits following exposure of the central nervous system to aluminum salts. These workers and others documented the appearance of prominent widespread neurofilamentous accumulations within days of introducing aluminum salts directly into the cerebral cortex or within the intrathecal space. ${ }^{8.9}$ These experimentally-induced neurofilamentous changes, on the light microscopic level of resolution, were originally thought to be similar to human neurofibrillary tangles.

Early electron microscopic studies led most investigators to consider the neurofibrillary tangle of human Alzheimer's disease to be composed of an altered microtubule (the so-called "twisted tubule"). ${ }^{10}$ Further ultrastructural evaluation modified this concept and the human neurofibrillary tangle is now considered to be composed of large numbers of pairs of $10 \mathrm{~nm}$. filamentous structures wound in a helical fashion, that is, the so-called paired-helical filament. ${ }^{11.12}$ The aluminum-induced tangles are composed of straight neurofilaments. ${ }^{7.10}$ Mechanisms for the formation of this unique paired-helical configuration remain unknown. The inherent resistance of these pairedhelical filaments to become solubilized following harsh proteolytic treatment has significantly hampered the biochemical analysis of this structure. ${ }^{13}$ However, recent antigenic evidence suggests that altered cytoskeletal proteins may form the basic components of paired-helical filaments. ${ }^{14.15}$

\section{Bulk Tissue Aluminum Analysis of Human Brain Tissues}

The existence of the rabbit animal model stimulated CrapperMcLachlin and his colleagues to determine the aluminum content of brain tissues collected from victims of Alzheimer's disease and of non-demented controls. In 1973, they reported that the brain aluminum content of Alzheimer's disease specimens was significantly elevated when compared to controls. ${ }^{16}$ Although dealing with regional bulk elemental content, they indicated that areas with the highest aluminum content tended to contain large numbers of neurofibrillary tangles. ${ }^{16,17}$ This work has been difficult to replicate and this subject remains controversial. ${ }^{18,19.20}$ All of these studies use brain tissue assay techniques (atomic absorption spectrometry and neutron activation analysis) which, by their very nature, involve a homogenization of a relatively large sample volume. In a situation of focal accumulation of an element in association with certain focal cellular lesions, dilution of that element within the relatively large total sample subjected to analysis might result in an inability to detect significant differences between affected and uninvolved tissues.

\section{Intracellular Aluminum Analysis in Alzheimer's Disease}

In our laboratory, we have developed techniques for the determination of the elemental content of individual neurons using scanning electron microscopy in conjunction with energy dispersive $\mathrm{x}$-ray analysis. ${ }^{21}$ The tissue to be analyzed is prepared as 20 micron thick frozen sections of formalin fixed brain samples. Large pyramidal neurons are identified for elemental analysis by examination of the secondary electron surface images or by the appearance of back-scattered electron images obtained from silver stained sections. Once a cell is selected for analysis, the electron beam is focussed to approximately one micron in diameter and is directed to a particular portion of the cell. This minute part of the tissue section is irradiated with the focussed electron beam, thus producing $\mathrm{x}$-rays. The $\mathrm{x}$-rays which are emitted from the tissue are characteristic in their energy levels for the elements contained within the irradiated portion of the target. By collecting and analyzing samples of the emitted $\mathrm{x}$-rays produced from selected portions of individual neurons, we have been able to provide information about their elemental content on a cell-by-cell basis.

Using this technique, we have detected intraneuronal accumulations of aluminum within neurofibrillary tangle-bearing neurons in the hippocampus of brains obtained from Alzheimer's disease patients. ${ }^{22}$ Adjacent tangle-free neurons in these cases, as well as similarly prepared age-matched controls, failed to show a similar degree of aluminum accumulation. These findings have been obtained in both silver stained preparations as well as unstained sections of severely involved tissues. ${ }^{23}$

\section{ALS/Parkinsonism-Dementia in the Guamanian Chamorro as a Model for Human Neurofibrillary Tangle-Formation}

Despite the fact that the neurofibrillary tangle is a pathologic hallmark of Alzheimer's disease, neurofibrillary tangles are encountered in association with a wide variety of other nervous system disorders. ${ }^{24}$ These include, among others, post-encephalitic parkinsonism, post-traumatic dementia (dementia pugilistica), Down's syndrome in middle age, subacute sclerosing panencephalitis (SSPE), certain cases of manganese and lead poisoning, and the parkinsonism dementia/ALS complex endemic to the native Chamorro people living on Guam. Although this list contains diseases with a wide range of etiologies (trauma, viruses, genetics, etc.), the underlying mechanism for neurofibrillary tangle formation in each specific clinical setting remains unknown.

The Chamorro are a group of indigenous people native to the island of Guam who show an inordinate tendency towards neurofibrillary tangle formation. Medical attention was originally attracted to this population when it was discovered, soon after World War II, that they suffered an extremely high incidence of a form of parkinsonism in association with severe dementia (parkinsonism-dementia of Guam) as well as of amyotrophic lateral sclerosis. ${ }^{25.26}$ Neuropathologic examination of the brains of cases of Guamanian parkinsonism-dementia showed a profound loss of pigmented neurons in the substantia nigra and widespread severe neurofibrillary tangle formation. ${ }^{27} \mathrm{Eval}$ uation of the amyotrophic lateral sclerosis cases from Guam showed the classic features of motor neuron degeneration and severe neurofibrillary tangle formation, a feature rarely encountered in ALS seen elsewhere in the world. ${ }^{28.29}$

Research activities related to the neurologic problems of the Guamanian Chamorros have centered primarily on attempts to determine underlying pathogenetic mechanisms responsible for their motor neuron degeneration. Dr. D. Carleton Gajdusek summarized the hope of many of the researchers involved in these studies when he wrote ". . . discovery of its cause and pathogenesis in these intensively affected populations will surely contribute to a better understanding of the disease (ALS) elsewhere. ${ }^{130}$ It has been our belief that the remarkable tendency of the Guamanian Chamorro to develop widespread severe neurofibrillary tangles represents a similar opportunity with respect to this aspect of Alzheimer's disease.

Accordingly, we have evaluated the trace elemental constituents of tangle-bearing and non-tangled hippocampal neurons of Guamanian Chamorros. In collaboration with the NIH-Labor- 
atory for Central Nervous System Studies, we have prepared brain tissue samples for intraneuronal trace element analysis. Using our techniques for scanning electron microscopy with $\mathrm{x}$-ray energy spectrometry, we have demonstrated that aluminum accumulates selectively within tangle-bearing neurons in the Guamanian Chamorro. ${ }^{31}$ Studies were conducted in which hippocampal brain sections were produced and $\mathrm{x}$-rays from individual neurons were collected and quantified under carefully standardized conditions. In this study the $x$-rays related to the presence of aluminum emitted from the tangle-bearing neurons were 3-4 times greater than those emitted from the neuronal populations analyzed from tangle-free Guamanian control samples. This dramatic accumulation of aluminum within the tangle-bearing neurons of the Guamanian Chamorro has now been independently confirmed using a different form of $\mathrm{x}$-ray spectrographic imaging. ${ }^{32}$

\section{Laser Microprobe Mass Analysis}

Recently, we have begun to apply laser microprobe mass analysis, or LAMMA, to this problem. ${ }^{33.34}$ This new technology allows elemental analysis of plastic embedded semi-thin tissue sections. The equipment (we utilize the LAMMA 500 manufactured by Leybold-Hereaus of W. Germany) produces a high energy laser beam pulse which is focussed onto the specimen by the objective of an optical microscope. The high energy laser is directed to the point of interest by a colinear $\mathrm{He}-\mathrm{Ne}$ continuous low energy laser which appears as a red spot on the semi-thin ( 0.5 micron thick) plastic embedded tissue section. The interaction of the high energy laser pulse with the tissue ionizes/vaporizes a microvolume of the section with a diameter of approximately one micron. The ions which are generated pass down the evacuated column of a time-of-flight mass spectrometer where they are separated and detected according to their mass number. The instrument has been linked to a dedicated Micro PDP-11/23 computer using an RT-11 operating system. Specific programs have been written to allow for the transfer and storage of mass spectra, calibration of the spectra, peak identification and peak height integration, spectral averaging and plotting. The details of the operation of the instrument and methods of analysis are provided elsewhere. ${ }^{33.35}$

Using this technology, we have begun to study the elemental constituents of tangle-bearing and tangle-free neurons of specimens derived from Guamanian ALS and tangle-free native controls. ${ }^{33.35 .36}$ While these studies are preliminary in nature, we have shown evidence of selective accumulation of aluminum within the tangle-bearing neurons of several of these Guamanian cases (Figures 1, 2).

\section{Discussion and Conclusions}

The nature and significance of the association of aluminum with the neurofibrillary tangle remains to be determined. Aluminum represents the third most common element on the surface of the earth and the most common metallic substance. Despite its abundance in the environment, aluminum is not generally considered to be essential for any biologic process. ${ }^{37}$ Although aluminum has been thought to be a relatively non-toxic substance, an increasing amount of data has emerged over the past several years to suggest that it may exert a deleterious effect on a number of biologic processes. This includes evidence that aluminum can produce cross-linking of DNA strands, ${ }^{38}$ can

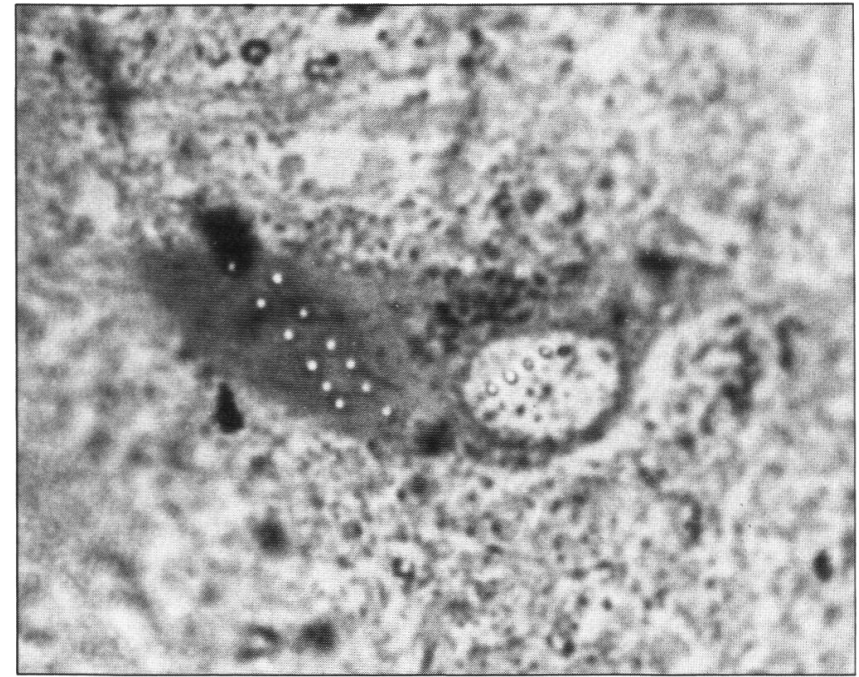

Figure I - Photomicrograph of a hippocampal neuron showing numerous intranuclear and cyroplasmic laser microprobe perforations. Each of these laser "shots" produces a resultant mass spectrum. (Toluidine blue stain of plastic embedded semi-thin section) Original magnification $320 \times$.

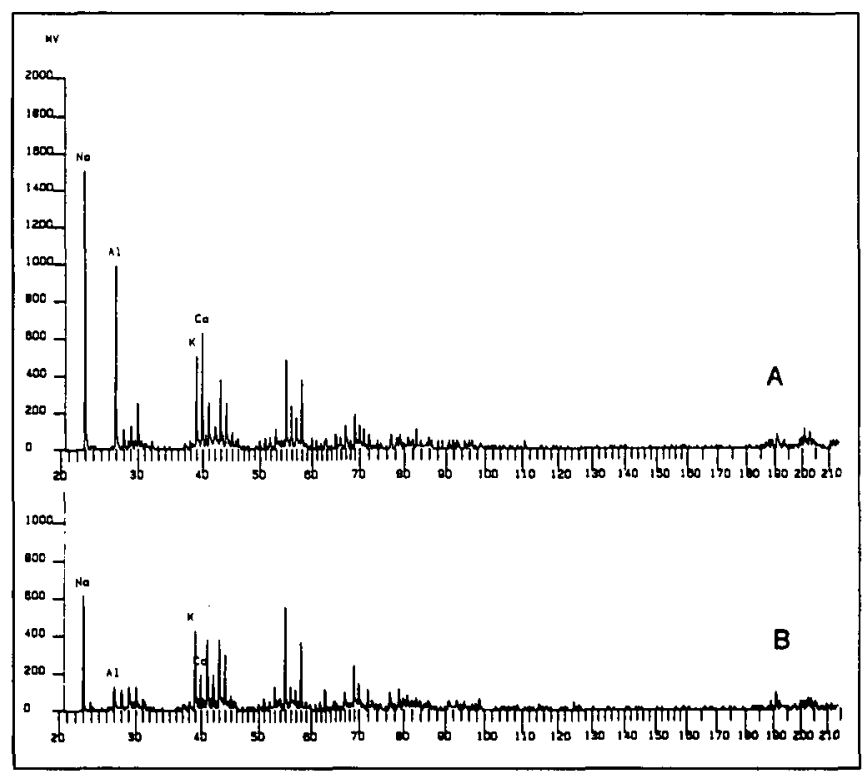

Figure 2 - Representative laser microprobe mass spectra from A) cytoplasm of neurofibrillary tangle-bearing neuron from the hippocampus of a brain specimen from a Guamanian ALS patient and B) neuropil adjacent to this neuron. Note the prominent peak related to the presence of aluminum from laser probe site $A$.

affect the activity of a number of enzyme systems ${ }^{39}$ including those involved in neurotransmitter function, ${ }^{40.41 .42 .43}$ and can bind competitively with calmodulin and affect its structural configuration. ${ }^{45,46}$

When aluminum gains access to the central nervous system of certain animal species, it acts as a potent neurotoxin. The element's accumulation in the nervous system of patients with Alzheimer's disease represents a finding which remains unexplained. Excessive or abnormal exposure to aluminum containing products does not seem to precede the development of 
Alzheimer's disease, ${ }^{46}$ although, considering the ubiquitous abundance of the element in our natural as well as commercial environment, the ability to take a reliable aluminum exposure history is quite limited. It is possible that Alzheimer's disease leads to a breakdown of the biologic barriers to aluminum's access to neurons.

Finally, we must consider the results of studies from the natives living on the island of Guam. As mentioned above, we originally approached Guam as a model system for neurofibrillary tangle formation. It is our feeling that an understanding of the pathogenesis of neurofibrillary tangle formation among the Guamanian Chamorro will provide important insights into neurofibrillary tangle formation in other settings. One conclusion, based on over thirty years of investigation, is that whatever mechanism is responsible for the unique epidemic of neurodegenerative diseases seen on Guam is related to the effects of environmental factors, with little influence of mutational events in the genetic pool. ${ }^{47.48,49} \mathrm{We}$ may then infer that certain environmental conditions on the island of Guam have led to the large numbers of neurofibrillary tangles seen in affected natives. Whether the accumulation of aluminum in neurofibrillary tanglebearing neurons causes this pathologic lesion or represents a secondary finding is still not clear. We anticipate that the search for an answer to this basic question will occupy our research activities for the next several years

\section{ACKNOWLEDGEMENTS}

This research has been conducted with the support of grants from the National Institutes of Health AG-01415, the John Douglas French Foundation and the Sandoz Corporation. The technical support of Judith Kessler and Michele Currier is also gratefully acknowledged.

\section{REFERENCES}

1. Alzheimer A. Ueber eine eigenartige Erkrankung der Hirnrinde. Allgemeine Z Psychiartr 1907; 64: 146-148.

2. Corsellis JNN. Aging and the dementias. In: Adams JH, Corsellis JAN, Duchen LW, eds. Greenfield's Neuropathology, 4th ed. New York: John Wiley, 1984: pp. 951-1025.

3. Tomlinson BE, Blessed G, Roth M. Observations on the brains of demented old people. J Neurol Sci 1970; 11: 205-242.

4. Tomlinson BE, Blessed G, Roth M. Observations on the brains of nondemented old people. J Neurol Sci 1968; 7: 331-356.

5. Dayan AD. Quantitative histological studies on the aged human brain. I. Senile plaques and neurofibrillary tangles in "normal" people. Acta Neuropath 1970; 16: 85-94.

6. Klatzo I, Wisniewski H, Streicher E. Experimental production of neurofibrillary degeneration. I. Light microscopic observations. J Neuropath Expt! Neurol 1965; 24: 187-199.

7. Terry RD, Pena C. Experimental production of neurofibrillary degeneration. 2. Electron microscopy, phosphatase histochemistry and electron probe analysis. J Neuropath Exptl Neurol 1965; 24: 200-210

8. Wisniewski HM, Narkewica O, Wisniewski K. Topography and dynamics of neurofibrillary degeneration in aluminum encephalopathy. Acta Neuropathol 1967; 9: 172-133.

9. Crapper DR, Dalton AJ. Alterations in short-term retention, conditioned avoidance response, acquisition and motivation following aluminum induced neurofibrillary degeneration. Physiol Behav 1973; 10: 925-933.

10. Terry RD. Electron microscopic studies of Alzheimer's disease and of experimental neurofibrillary tangles. In: Bailey OT, Smith DE, eds. The Central Nervous System. Baltimore, Williams \& Wilkins, 1968: 213-224
11. Kidd M. Paired helical filaments in electron microscopy of Alzheimer's disease. Nature 1963; 197: 192-193.

12. Wisniewski HM, Narang HK, Terry RD. Neurofibrillary tangles of paired helical filaments. J Neurol Sci 1976; 27 : 173-181.

13. Selkoe DJ, Ihara Y, Salazar FJ. Alzheimer's disease: insolubility of partially purified paired helical filaments in sodium dodecyl sulfate and urea. Science 1982; 215: 1243-1245.

14. Anderton BH, Breinburg D, Downes MJ, et al. Monoclonal antibodies show that neurofibrillary tangles and neurofilaments share antigenic determinants. Nature $1982 ; 298: 84-86$.

15. Gambetti P, Autulio-Gambetti L, Perry G, et al. Antibodies to neurofibrillary tangles of Alzheimer's disease from human and animal neurofilament fractions. Lab Invest 1983; 49: 430-435.

16. Crapper DR, Krishnan SS Dalton AJ. Brain aluminum distribution in Alzheimer's disease and especially neurofibrillary degeneration. Science 1973; 180: $511-513$.

17. Crapper DR, Krishnan SS, Quirrkat S. Aluminum, neurofibrillary degeneration and Alzheimer's disease. Brain 1976; 99: 67-80.

18. Markesbury WR, Ehmann WD, Hossain TIM, et al. Instrumental neutron activation analysis of brain aluminum in Alzheimer's disease and aging. Ann Neurol 1981; 10: 511-516.

19. McDermott JR, Smith AI, Igbal K, et al. Brain aluminum in aging and Alzheimer disease. Neurology 1979; 29: 809-814.

20. Trapp GA, Miner GD, Zimmerman, et al. Aluminum levels in brain in Alzheimer's disease. Biol Psychiat 1978; 13: 709-718.

21. Perl DP. Detection of aluminum in nervous system tissues by scanning electron microscopy. In: Wills MR, Savory J, eds. Aluminum Analysis in Biological Materials. Charlottesville, VA: Univ. Virginia Press, 1983: 34-44.

22. Perl DP, Brody AR. Alzheimer's disease: X-ray spectrometric evidence of aluminum accumulation in neurofibrillary tanglebearing neurons. Science 1980; 208: 297-299.

23. Perl DP, Pendlebury WW. Aluminum accumulation in neurofibrillary tangle-bearing neurons of senile dementia, Alzheimer's type - detection by intraneuronal X-ray spectrometry studies of unstained tissue sections. J Neuropath Exptl Neurol 1984; 43: 349.

24. Wisniewski K, Jervis GA, Moretz RC, et al. Alzheimer neurofibrillary tangles in diseases other than senile and presenile dementia. Ann Neurol 1979; 5: 288-294.

25. Kurland LT, Mulder DW. Epidemiologic investigations of amyotrophic lateral sclerosis. Neurology 1954; 4: 355-378.

26. Hirano A, Kurland LT, Krooth RS, et al. Parkinsonism-dementia complex, an endemic disease on the island of Guam. - I. Clinical features. Brain 1961; 84: 642-661.

27. Hirano A, Malamud N, Kurland LT. Parkinsonism-dementia comples, an endemic disease on the island of Guam. II. Pathological features. Brain 1961; 84: 662-679.

28. Malamud N, Hirano A, Kurland LT. Pathoanatomic changes in amyotrophic lateral sclerosis on Guam. Special reference to the occurrence of neurofibrillary changes. Arch Neurol 1961;29: 573.578

29. Hirano A, Arumugasamy N, Zimmerman HM. Amyotrophic lateral sclerosis: a comparison of Guam and classical cases. Arch Neurol 1967; 16: 357-363.

30. Gajdusek DC. Foci of motor neuron disease in high incidence in isolated populations of East Asia and the Western Pacific. In Rowland LP, ed. Advances in Neurology: Human Motor Neuron Diseases. New York: Raven Press, 1982; 36: 363-394.

31. Perl DP, Gajdusek DC, Garruto RM, et al. Intraneuronal aluminum accumulation in amyotrophic lateral sclerosis and parkinsonism dementia of Guam. Science 1982; 217: 1053-1054.

32. Garruto RM, Fukatsu R, Yangihara R, et al. Imaging of calcium and aluminum in neurofibrillary tangle-bearing neurons in parkinsonism-dementia of Guam. Proc Natl Acad Sci (USA) 1984; 81: 1875-1879.

33. Perl DP, Munoz-Garcia D, Good PF, et al. Laser microprobe mass analyzer (LAMMA) - a new approach to the study of the association of aluminum and neurofibrillary tangle formation. In: Fisher A, Hanin I, eds. Alzheimer's and Parkinsons' Diseases. New York: Plenum, 1986; 241-248.

34. Perl DP, Munoz-Garcia D, Good PF, et al. Intracytoplasmic aluminum accumulation in neurofibrillary tangle-bearing neurons: detection by laser microprobe mass analyzer (LAMMA). Ann Neurol 1985; 34: 264. 
35. Heinen HJ, Hillenkamp F, Kaufmann R, et al. LAMMA: A new laser microprobe mass analyzer for biomedicine and biological materials analysis. In: Frigerio A, McCamish M, eds. Recent Developments in Mass Spectometry in Biochemistry and Medicine. Amsterdam: Elsevier, 1980: 435-451.

36. Perl DP, Munoz-Garcia D, Good PF, et al. Calculation of intracellular aluminum concentration in neurofibrillary tangle (NFT) bearing and NFT-free neurons of ALS/Parkinsonism dementia (PD) of Guam using laser microprobe mass analysis (LAMMA). J Neuropath Exptl Neurol 1986; 45: 379.

37. Underwood EJ. Trace Elements in Human and Animal Nutrition. New York: Academic Press, 1977: p. 430.

38. Karlick SJ, Eichhorn GL, Lewis PN, et al. Interaction of aluminum species with deoxyribonucleic acid. Biochemistry 1980; 19: 5991-5998.

39. Lai JCK, Blass JP. Inhibition of brain glycolysis by aluminum. J Neurochem 1984; 42: 438-446.

40. Wenk GL, Stemmer KL. Activity of the enzymes dopamine-betahydroxylase and phenylethanolamine- $\mathrm{N}$-methyltransferase in discrete brain regions of the copper-zinc deficient rat following aluminum ingestion. Neurotoxicology 1982; 3: 93-99.

41. Marquis JK, Lerrick AJ. Noncompetitive inhibition by aluminum, scandium, and yttrium of acetylcholinesterase from "electrophorus electricus". Biochem Pharmacology 1982;31: 1437-1440.
42. Kosik KS, Bradley WG, Good PF, et al. Cholinergic function in lumbar aluminum myelopathy. J Neurpath Exptl Neurol 1983; 42: 365-375.

43. Yates CM, Simpson J, Russell D, et al. Cholinergic enzymes in neurofibrillary degeneration produced by aluminum. Brain Res 1980; 197: 269-274.

44. Siegal N, Coughlin R, Haug A. A thermodynamic and electron paramagnetic resonance study of structural changes in calmodulin induced by aluminum binding. Biochem Biophys Res Comm $1983 ; 115: 512-517$

45. Siegel N, Suhayda C, Haug A. Aluminum changes the conformation of calmodulin. Physiol Chem Physics 1982; 14: 165-169.

46. Heyman A, Wilkinson WE, Stafford JA, et al. Alzheimer's disease: a study of epidemiological aspects. Ann Neurol 1984; 15: 335-341.

47. Yase $Y$. The pathogenesis of amyotrophic lateral sclerosis. Lancet 1972; ii: 292-296.

48. Reed DM, Brody JA. Amyotrophic lateral sclerosis and parkinsonism-dementia on Guam, 1945-1972. I. Descriptive epidemiology. Amer J Epidemiol 1975; 101: 287-301.

49. Garruto RM, Yanagihara R, Gajdusek DC. Disappearance of highincidence amyotrophic lateral sclerosis and parkinsonism-dementia on Guam. Neurology 1985; 35: 193-198. 